\title{
X-Ray and NMR spectroscopic characterisation of cyclic titanodiphenylsiloxanes and examination of the hydrolytic stability of their $\mathrm{Si} O \mathrm{O}$ Ti bonds
}

\author{
Dagobert Hoebbel, ${ }^{* a}$ Manfred Nacken, ${ }^{a}$ Helmut Schmidt, ${ }^{a}$ Volker Huch ${ }^{b}$ and Michael Veith ${ }^{b}$ \\ ${ }^{a}$ Institut für Neue Materialien, Im Stadtwald, 66123 Saarbrücken, Germany \\ ${ }^{b}$ Institut für Anorganische Chemie, Universität des Saarlandes, 66123 Saarbrücken, Germany
}

\begin{abstract}
Six crystalline titanodiphenylsiloxanes have been synthesised by reaction of diphenylsilanediol (DPSD) with titanium tetraisopropoxide or its complexes with acetylacetonate (acac) as ligand. Two of them show a spirocyclic structure with the formula $\mathrm{TiO}_{2}\left[\mathrm{O}_{2} \mathrm{Si}_{2}\left(\mathrm{C}_{6} \mathrm{H}_{5}\right)_{4}\right]_{2} \mathbf{A}$ and $\mathrm{TiO}_{2}\left[\mathrm{O}_{4} \mathrm{Si}_{4}\left(\mathrm{C}_{6} \mathrm{H}_{5}\right)_{8}\right]_{2} \mathbf{B}$ which have already been described in the literature. Two compounds $\mathbf{C}$ and $\mathbf{D}$ were identified by $\mathrm{X}$ ray analysis to have the same bicyclic structure but different coordinating solvent molecules. Tetrahydrofuran acts as a non bridging ligand at the Ti atoms in $\left[\text { Ti(acac) } \mathrm{O}_{1.5}\right]_{2}\left[\mathrm{OSi}_{(}\left(\mathrm{C}_{6} \mathrm{H}_{5}\right)_{2}\right]_{3} \cdot 2 \mathrm{C}_{4} \mathrm{H}_{8} \mathrm{O} \mathrm{C}$ while dioxane acts as a bridging ligand between the Ti atoms of neighbouring molecules of $\left[\mathrm{Ti}(\mathrm{acac}) \mathrm{O}_{1.5}\right]_{2}\left[\mathrm{OSi}_{(}\left(\mathrm{C}_{6} \mathrm{H}_{5}\right)_{2}\right]_{3} \cdot 3 \mathrm{C}_{4} \mathrm{H}_{8} \mathrm{O}_{2} \mathbf{D}$. The titanodiphenylsiloxanes $\mathbf{E}$ and $\mathbf{F}$ were identified by a cyclotetrameric structure and the formulas $\left[\mathrm{Ti}(\mathrm{acac})_{2} \mathrm{O}\right]_{2}\left[\mathrm{OSi}\left(\mathrm{C}_{6} \mathrm{H}_{5}\right)_{2}\right]_{2}$ and $\left[\mathrm{Ti}(\mathrm{acac})_{2} \mathrm{O}\right]\left[\mathrm{OSi}\left(\mathrm{C}_{6} \mathrm{H}_{5}\right)_{2}\right]_{3}$, respectively. The titanodiphenylsiloxanes $\mathbf{A} \mathbf{E}$ were characterised by ${ }^{29} \mathrm{Si}$ and ${ }^{17} \mathrm{O} \mathrm{NMR}$ spectroscopy, IR and time of flight mass spectrometry measurements. The hydrolytic stabilities of the $\mathrm{Si}-\mathrm{O}-\mathrm{Ti}$ bonds in the titanodiphenylsiloxanes A E have been examined mainly by means of ${ }^{29} \mathrm{Si}$ NMR spectroscopy. The results reveal a strong influence of the structure type of the titanodiphenylsiloxanes on the hydrolytic stability of their $\mathrm{Si}-\mathrm{O}-\mathrm{Ti}$ bonds apart from the hydrolytic conditions (amount of water, $\mathrm{Si}$, Ti and $\mathrm{H}^{+}$concentration). The hydrolytic stability of the titanodiphenylsiloxanes $\mathbf{A}$ E decreases in the order cyclotetramer $(\mathbf{E})>\operatorname{spirocyclo}(\mathbf{A}, \mathbf{B})>$ bicyclo $(\mathbf{C}, \mathbf{D})$. Reasons for the different hydrolytic stability are discussed. The results on the different hydrolytic stabilities of $\mathrm{Si}-\mathrm{O}-\mathrm{Ti}$ bonds can contribute to a better understanding of the synthesis of homogeneous heterometal materials on a molecular scale via the sol gel process.
\end{abstract}

Oxygen bridged heterometal bonds e.g. $\mathrm{Si}-\mathrm{O}-\mathrm{Al}, \mathrm{Si}-\mathrm{O}-\mathrm{Ti}$ or $\mathrm{Si}-\mathrm{O}-\mathrm{Zr}$ are important in terms of the structure and properties of glasses, ceramics and hybrid polymers. In addition to high temperature processes the sol gel process is an often used method for the preparation of materials with heterometal bonds, starting from mixtures of metal alkoxides or their organic derivatives. ${ }^{15}$ Until now, there is insufficient know ledge concerning the existence and the amount of heterometal bonds and their hydrolytic stability in the course of the sol gel process. ${ }^{6} 10$ The knowledge of the stability of heterometal bonds, however, is a basis for the preparation of homogeneous heterometal materials on a molecular scale. Recently, it has been shown that $\mathrm{Si}-\mathrm{O}-\mathrm{Ti}$ and $\mathrm{Si}-\mathrm{O}-\mathrm{Zr}$ bonds in sol gel systems are hydrolysed and converted to $\mathrm{SiO}_{2}$ and $\mathrm{TiO}_{2}$ or $\mathrm{ZrO}_{2}$ rich phases which lower the homogeneity of sol gel derived materials. ${ }^{11}{ }^{14}$ Previous work on the hydrolytic stab ility of the heterometal bonds has been carried out mainly on mixtures of different metal alkoxide hydrolysates with a wide distribution of unidentified species. The objective of this work is to reveal, for well defined cyclic titanodiphenylsiloxanes, the influence of the structure on the hydrolytic stability of $\mathrm{Si}-\mathrm{O}-\mathrm{Ti}$ bonds, which is important with respect to the synthesis of materials with high homogeneity at the molecular scale via the sol gel process.

\section{Experimental}

\section{Synthesis}

Generally, the crystalline titanodiphenylsiloxanes were syn thesised by reaction of diphenylsilanediol (DPSD) or tetra phenyldisiloxanediol with titanium tetraalkoxides or its complexes with acetylacetone (Hacac).

Spirocyclic titanodiphenylsiloxane $\mathrm{TiO}_{2}\left[\mathrm{O}_{2} \mathrm{Si}_{2}\left(\mathrm{C}_{6} \mathrm{H}_{5}\right)_{4}\right]_{2}$ A. The crystalline compound was synthesised by reaction of tetraphenyldisiloxanediol ${ }^{13}$ with titanium tetraisopropoxide at a molar ratio of $2: 1$ according to the procedure of Andrianov et $a .^{15,16}$ Tetraphenyldisiloxanediol $(1 \mathrm{~g}, 2.42 \mathrm{mmol})$ was dis solved in $3.47 \mathrm{ml}$ dioxane and $0.356 \mathrm{ml}(1.21 \mathrm{mmol})$ of $\mathrm{Ti}\left(\mathrm{OPr}^{\mathrm{i}}\right)_{4}$ were added dropwise under vigorous stirring at $25^{\circ} \mathrm{C}$. Colourless crystals were formed from the transparent solution in a yield of $30 \%$ after $1 \mathrm{~h}$ reaction time.

Spirocyclic titanodiphenylsiloxane $\mathrm{TiO}_{2}\left[\mathrm{O}_{4} \mathrm{Si}_{4}\left(\mathrm{C}_{6} \mathrm{H}_{5}\right)_{8}\right]_{2}$ B. The synthesis was carried out according to the literature. ${ }^{17}$ DPSD (10 g, $46.2 \mathrm{mmol}$ ) dissolved in $21 \mathrm{ml}$ diethyl ether was mixed with $7.86 \mathrm{ml}(22.96 \mathrm{mmol})$ of titanium tetra $n$ butoxide at a molar ratio of $2: 1$. Colorless crystals were obtained after reflux of the solution for $30 \mathrm{~min}$ and stirring of $2 \mathrm{~h}$. The crystals were recrystallised from toluene with a yield of $28 \%$.

Bicyclic titanodiphenylsiloxanes $\quad\left[\mathrm{Ti}(\text { acac }) \mathrm{O}_{1.5}\right]_{2}[\mathrm{OSi}-$ $\left.\left(\mathrm{C}_{6} \mathrm{H}_{5}\right)_{2}\right]_{3} \cdot 2 \mathrm{C}_{4} \mathrm{H}_{8} \mathrm{O} C$ and $\left[\mathrm{Ti}(\mathrm{acac}) \mathrm{O}_{1.5}\right]_{2}\left[\mathrm{OSi}\left(\mathrm{C}_{6} \mathrm{H}_{5}\right)_{2}\right]_{3} \cdot 3$ $\mathbf{C}_{4} \mathbf{H}_{8} \mathbf{O}_{2}$ D. DPSD $(4 \mathrm{~g}, 18.52 \mathrm{mmol})$ dissolved in $7.41 \mathrm{ml}$ tetrahydrofuran (THF) was mixed with $4.08 \mathrm{ml}(13.86 \mathrm{mmol})$ of titanium tetraisopropoxide and $1.43 \mathrm{ml}(13.89 \mathrm{mmol})$ of acetylacetone in $2 \mathrm{ml}$ of THF at the molar ratio of $1: 0.75$. Colourless crystals of $\mathbf{C}$ were formed from the solution after $2 \mathrm{~h}$ reaction time with a yield of $35 \%$. The bicyclic titano diphenylsiloxane $\mathbf{D}$ was synthesised with a yield of $25 \%$ by the same procedure but with dioxane as solvent.

Cyclotetrameric titanodiphenylsiloxanes $\left[\mathrm{Ti}(\operatorname{acac})_{2} \mathrm{O}_{2}-\right.$ $\left[\mathrm{OSi}\left(\mathrm{C}_{6} \mathrm{H}_{5}\right)_{2}\right]_{2} \mathrm{E}$ and $\left[\mathrm{Ti}(\operatorname{acac})_{2} \mathrm{O}\right]\left[\mathrm{OSi}\left(\mathrm{C}_{6} \mathrm{H}_{5}\right)_{2}\right]_{3} \mathrm{~F}$. A solu tion of $1.36 \mathrm{ml}(4.62 \mathrm{mmol})$ titanium tetraisopropoxide and $0.95 \mathrm{ml}(9.23 \mathrm{mmol})$ acetylacetone in $1 \mathrm{ml}$ dioxane was aged for $1 \mathrm{~h}$ and then added to a solution of $1 \mathrm{~g}$ of $(4.62 \mathrm{mmol})$ DPSD in $5.03 \mathrm{ml}$ dioxane. Yellow crystals of $\mathbf{E}$ were formed from the transparent solution after $10 \mathrm{~min}$ with a yield of $90 \%$. A solution of $1.38 \mathrm{~g}$ titanodiphenylsiloxane $\mathbf{C}$ in $5.1 \mathrm{ml} \mathrm{THF}$ was hydrolysed with water at the molar ratio $\mathrm{H}_{2} \mathrm{O} / \mathrm{Ti}=20$. Crystals of F $(0.22 \mathrm{~g}$, yield $=20 \%)$ were obtained after $24 \mathrm{~h}$ reaction time. 
Table 1 Crystal data of the $\mathrm{X}$ ray diffraction studies $^{a}$

\begin{tabular}{|c|c|c|c|c|}
\hline compound & $\mathbf{C}$ & $\mathbf{D}$ & $\mathbf{E}$ & $\mathbf{F}$ \\
\hline $\begin{array}{l}\text { formula } \\
\text { crystal system }\end{array}$ & $\begin{array}{l}\mathrm{C}_{54} \mathrm{H}_{60} \mathrm{O}_{12} \mathrm{Si}_{3} \mathrm{Ti}_{2} \\
\text { triclinic }\end{array}$ & $\begin{array}{l}\mathrm{C}_{50} \mathrm{H}_{52} \mathrm{O}_{12} \mathrm{Si}_{3} \mathrm{Ti}_{2} \cdot \mathrm{C}_{4} \mathrm{H}_{8} \mathrm{O}_{2} \\
\text { monoclinic }\end{array}$ & $\begin{array}{l}\mathrm{C}_{44} \mathrm{H}_{48} \mathrm{O}_{12} \mathrm{Si}_{2} \mathrm{Ti}_{2} \cdot \mathrm{C}_{4} \mathrm{H}_{8} \mathrm{O}_{2} \\
\text { triclinic }\end{array}$ & $\begin{array}{l}\mathrm{C}_{46} \mathrm{H}_{44} \mathrm{O}_{8} \mathrm{Si}_{3} \mathrm{Ti} \\
\text { triclinic }\end{array}$ \\
\hline space group & $P 1$ & $C 2 / c$ & $P 1$ & $P 1$ \\
\hline$a / \AA$ & $13.927(3)$ & $21.896(4)$ & $8.96(2)$ & $10.703(2)$ \\
\hline$b / \AA$ & $20.158(4)$ & $14.048(3)$ & $11.46(2)$ & $11.381(2)$ \\
\hline$c / \AA$ & $20.319(4)$ & $20.275(4)$ & $13.38(3)$ & $18.762(4)$ \\
\hline$\alpha /$ degrees & $91.75(3)$ & & $86.0(2)$ & $98.35(3)$ \\
\hline$\beta /$ degrees & $99.02(3)$ & 95.94(3) & $74.8(2)$ & $90.12(3)$ \\
\hline$\gamma /$ degrees & $90.10(3)$ & & $70.7(2)$ & $92.25(3)$ \\
\hline$V / \AA^{3}$ & $5631(2)$ & $6203(2)$ & $1251(5)$ & $2259.4(8)$ \\
\hline$Z$ & 4 & 4 & 1 & 2 \\
\hline$D_{\mathrm{c}} / \mathrm{Mg} \mathrm{m}^{3}$ & 1.275 & 1.286 & 1.340 & 1.260 \\
\hline$\mu(\mathrm{MoK} \alpha) / \mathrm{mm}^{1}$ & 0.405 & 0.379 & 0.430 & 0.319 \\
\hline diffractometer & Stoe IPDS & Stoe IPDS & Stoe AED2 & Stoe IPDS \\
\hline temperature/K & 293 & 293 & 293 & 293 \\
\hline collected data & 37322 & 24406 & 3271 & 22119 \\
\hline unique reflections & 13813 & 4711 & 3271 & 8195 \\
\hline$R_{\text {merge }}$ & 0.06 & 0.05 & & 0.04 \\
\hline $\begin{array}{l}\text { observed reflections } \\
(I>2 \sigma I)\end{array}$ & 10828 & 3682 & 2642 & 6649 \\
\hline parameters & 1279 & 327 & 291 & 523 \\
\hline$R_{1}$ & 0.072 & 0.066 & 0.0561 & 0.043 \\
\hline$w \mathbf{R}_{2}$ & 0.1970 & 0.173 & 0.1506 & 0.125 \\
\hline $\begin{array}{l}\text { largest difference } \\
\text { peak, hole/e } \AA 3\end{array}$ & $1.036, \quad 0.536$ & $0.803, \quad 0.750$ & $0.658, \quad 0.259$ & $0.274, \quad 0.298$ \\
\hline
\end{tabular}

${ }^{a}$ The programs SHELXS and SHELXL were used to solve and refine the structures. ${ }^{29}{ }^{b} R_{1}=\sum\left\|F_{\mathrm{O}}|\quad| F_{\mathrm{c}}\right\| / \sum\left|F_{\mathrm{O}}\right|, w R_{2}=\left\{\sum\left[w\left(F_{\mathrm{O}}{ }^{2} \quad F_{\mathrm{c}}{ }^{2}\right)^{2}\right] /\right.$ $\left.\sum\left[w\left(F_{\mathrm{O}}{ }^{2}\right)^{2}\right]\right\}^{1 / 2}$.

${ }^{17} \mathrm{O}$ labelled DPSD was used for the preparation of the ${ }^{17} \mathrm{O}$ doped tetraphenyldisiloxanediol ${ }^{18}$ and ${ }^{17} \mathrm{O}$ labelled titanodi phenylsiloxanes, ${ }^{13}$ as described above.

\section{X-Ray crystallographic analysis}

Single crystals of compounds $\mathbf{C}, \mathbf{D}, \mathbf{E}$ and $\mathbf{F}$ were used for $\mathbf{X}$ ray diffraction studies with data being assembled in Table 1. Complete lists of atomic positional parameters, tempera ture factors, bond lengths, angles and $F_{\mathrm{o}} / F_{\mathrm{c}}$ values have been deposited at the Fachinformationszentrum Karlsruhe, Gesellschaft für wissenschaftlich technische Information $\mathrm{mbH}$, D 76344 Eggenstein Leopoldshafen (Germany) on quoting the depository numbers CSD 407304 (C), CSD 407305 (D), CSD $407306(\mathrm{E})$ and CSD $407307(\mathrm{~F}) \cdot \dagger$

\section{Hydrolysis}

In a first series of experiments the titanodiphenylsiloxanes A D were dissolved in tetrahydrofuran with molar Si concen tration $>0.5 \mathrm{moll}^{-1}\left(0.05 \mathrm{moll}^{-1}\right.$ for compound E). A water THF solution was added at the molar ratios $(H)$ $\mathrm{H}_{2} \mathrm{O}: \mathrm{Ti}=1$ and 6 at $25^{\circ} \mathrm{C}$ under vigorous stirring. The final $\mathrm{Si}$ concentration in the hydrolysates A $\mathbf{D}$ amounts to 0.5 and in $\mathbf{E}$ to $0.048 \mathrm{~mol}^{-1}$. In a second series of experiments the amount of water was related to the number of hydrolysable $\mathrm{Si}-\mathrm{O}-\mathrm{Ti}$ bonds. The molar ratio $(K) \mathrm{H}_{2} \mathrm{O}:(\mathrm{Si}-\mathrm{O}-\mathrm{Ti})$ of 1:1 was used for the titanodiphenylsiloxanes $\mathbf{A} \mathbf{E}$. The Ti concentration in the hydrolysates $\mathbf{A} \mathbf{D}$ was kept in the range $0.160 .23 \mathrm{~mol} \mathrm{l}^{-1}$ and in the hydrolysate $\mathbf{E}$ at $0.048 \mathrm{~mol} \mathrm{l}^{-1}$.

For comparison, the spirocyclic titanosiloxane $\mathbf{B}$ was hydro lysed in a concentrated $\left[c(\mathrm{Ti})=0.16 \mathrm{~mol}^{-1}\right]$ and dilute solu tion $\left(0.023 \mathrm{~mol} \mathrm{l}^{-1}\right)$. The hydrolytic stability of compound $\mathbf{F}$, a reaction product of the hydrolysis of the titanodiphenylsilox anes $\mathbf{C}$ and $\mathbf{D}$, was not examined in this work.

$\dagger$ Full crystallographic details, excluding structure factors, have been deposited at the Cambridge Crystallographic Data Centre (CCDC). See Information for Authors, J. Mater. Chem., 1998, Issue 1. Any request to the $\mathrm{CCDC}$ for this material should quote the full literature citation and the reference number $1145 / 60$.

\section{NMR measurements}

${ }^{29} \mathrm{Si}$ and ${ }^{17} \mathrm{O}$ NMR spectra were obtained using a liquid state spectrometer (Bruker AC 200) operating at a field of $4.7 \mathrm{~T}$. ${ }^{29} \mathrm{Si}$ NMR: external reference: tetramethylsilane, internal stan dard: phenyltrimethylsilane, repetition time: $40 \mathrm{~s}$, pulse angle: $63^{\circ}$, number of scans: 90180 . The dilute solutions of $\mathbf{B}$ and $\mathbf{E}$ $\left[c(\mathrm{Ti})=0.024\right.$ and $0.048 \mathrm{~mol} \mathrm{l}^{-1}$, respectively] were recorded for $12 \mathrm{~h}$. The time of hydrolysis specified results from the averaged time between the start and end of the NMR measure ment. The quantitative data are obtained from the integrated signal intensities of the samples in comparison with the signal intensity of the internal phenyltrimethylsilane standard. ${ }^{17} \mathrm{O}$ NMR: the samples were enriched with ${ }^{17} \mathrm{O}$, single pulse experi ment, repetition time: $600 \mathrm{~ms}$, pulse angle: $90^{\circ}$, reference $\mathrm{H}_{2} \mathrm{O}$ $\left(1 \%{ }^{17} \mathrm{O}\right)$, number of scans 400010000 . The solid state ${ }^{29} \mathrm{Si}$ NMR spectra were recorded using a Bruker MSL $200 \mathrm{spec}$ trometer at $4.7 \mathrm{~T}$ and the ${ }^{29} \mathrm{Si}\left\{{ }^{1} \mathrm{H}\right\}$ inverse gated sequence. External standard: $\left[\left(\mathrm{CH}_{3}\right)_{3} \mathrm{Si}_{8} \mathrm{Si}_{8} \mathrm{O}_{20}\left(\mathrm{Q}_{8} \mathrm{M}_{8}\right)\right.$, MAS: $3 \mathrm{kHz}$, pulse angle $63^{\circ}$, repetition time: $60 \mathrm{~s}, 2001000$ scans.

\section{Time-of-flight (TOF) mass spectrometry and FTIR} measurements

A TOF Kompact MALDI III equipped with $\mathrm{N}_{2}$ laser (Shimadzu) was used for the determination of the molecular masses of the titanodiphenylsiloxanes. Conditions: positive reflectron mode, $20 \mathrm{kV}$ acceleration voltage, $\mathrm{Ag}$ doped nicotin acid amide or nitrophenyl octyl ether as matrix and dioxane or THF as solvents.

The FTIR spectra were obtained using a Bruker IFS25 spectrometer. The $\mathrm{KBr}$ sample pellet was formed by mixing $200 \mathrm{mg} \mathrm{KBr}$ with $1 \mathrm{mg}$ of the titanodiphenylsiloxane.

\section{Results and Discussion}

\section{Structural analysis of the titanodiphenylsiloxanes}

Six titanodiphenylsiloxanes (Fig. 1) were synthesised and characterised by $\mathrm{X}$ ray structural analysis and spectroscopic methods (NMR, molecular mass, IR). Five of them (A E) 

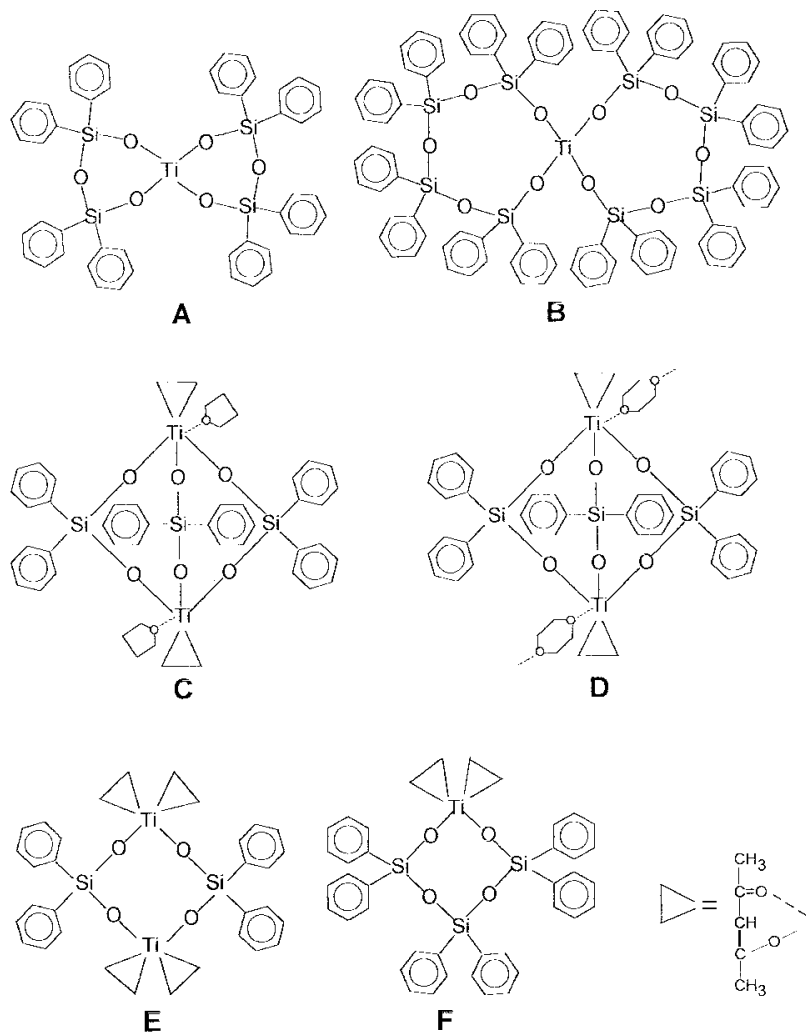

Fig. 1 Structural scheme of the titanodiphenylsiloxanes A F

were used for the investigation of the hydrolytic stability of $\mathrm{Si}-\mathrm{O}-\mathrm{Ti}$ bonds in different structures. Titano diphenylsiloxane $\mathbf{A}$ has been described by Andrianov et al. ${ }^{15,16}$ in 1976 and was identified by its composition and its physico chemical properties as a spirocyclic compound (Fig. 1, A). The structure of the spirocyclic titanodiphenylsiloxane $\mathbf{B}$ was ident ified by means of $\mathrm{X}$ ray analysis. ${ }^{19}$ The $\mathrm{X}$ ray structural analyses of the titanodiphenylsiloxanes $\mathbf{C}, \mathbf{D}, \mathbf{E}$ and $\mathbf{F}$ were carried out in this work. Fig. 2 shows the structures of $\mathbf{C}$ and E. Compounds $\mathbf{C}$ and $\mathbf{D}$ have a central eleven membered bicyclic $\mathrm{Ti}_{2} \mathrm{O}_{6} \mathrm{Si}_{3}$ cage as the central unit, and $\mathbf{E}$ and $\mathbf{F}$ have a simple eight membered $\mathrm{Si}_{2} \mathrm{O}_{4} \mathrm{Ti}_{2}$ and $\mathrm{Si}_{3} \mathrm{O}_{4} \mathrm{Ti}$ ring, respect ively. The titanium atoms in all cases are hexa coordinated by oxygen atoms and the silicon atoms are in a distorted tetra hedral environment formed by oxygen atoms and two carbon atoms of the phenyl groups. In compounds $\mathbf{C}$ and $\mathbf{D}$, one acetylacetonate group is bonded to the Ti atom in the usual chelating form and tetrahydrofuran or dioxane molecules complete the coordination sphere. In the crystal structure of D, besides the dioxane molecule bonded to titanium and bridged to a neighbouring molecule, two other dioxane mol ecules are present in the crystal which have no bonds to $\mathrm{Ti}$ or $\mathrm{Si}$ and seem to serve as space filling molecules. The most pertinent bond lengths and angles of compounds $\mathbf{C}, \mathbf{D}, \mathbf{E}$ and $\mathbf{F}$ are listed in Table 2. The experimental values compare well with standard $\mathrm{Si}-\mathrm{O}^{19}$ and $\mathrm{Ti}-\mathrm{O}^{20,21}$ bond lengths. Similar $-\mathrm{O}-\mathrm{SiPh}_{2}-\mathrm{O}-\mathrm{SiPh}_{2}-\mathrm{O}-$ bridges have been recently described for aluminopolysiloxanes with geometrically ana logous dimensions. ${ }^{22}$

\section{Spectroscopic characterisation of the titanodiphenylsiloxanes}

Results of the ${ }^{29} \mathrm{Si}$ and ${ }^{17} \mathrm{O}$ NMR characterisation, molecular masses and elemental analyses of the crystalline titanodiphenyl siloxanes $\mathbf{A} \mathbf{E}$ are summarised in Table 3. Compound $\mathbf{F}$, a reaction product of the hydrolysis of samples $\mathbf{C}$ and $\mathbf{D}$, was not studied. Generally, the results of the elemental analysis of the compounds $\mathbf{A} \mathbf{E}$ and those of the determination of molecu lar masses by time of flight (TOF) measurements are in accord ance with the crystal structures.

It is remarkable that the THF coordinated compound $\mathbf{C}$ shows the signal for the molecular mass of the basic structure $\left(\mathrm{M}+\mathrm{Na}^{+}=959\right)$ without the coordinating solvent in the TOF spectrum. Probably, the bonding of the solvent in the molecules is too weak for the identification of the actual molecular mass (1080) under TOF conditions. No TOF spectrum was obtained from the compound $\mathbf{D}$ using dioxane as solvent.

The ${ }^{29} \mathrm{Si}$ NMR spectra of THF solutions of the titanodiphen ylsiloxanes $\mathbf{A}, \mathbf{C}, \mathbf{D}$ and $\mathbf{E}$ with always one type of chemically equivalent $\mathrm{Si}$ atoms show, in accordance with their structures, one signal with a chemical shift $\delta$ in the region between 44 and 49 (Table 3 ). It should be noted that the ${ }^{29} \mathrm{Si} \mathrm{NMR}$ spectra of the bicyclic compounds $\mathbf{C}$ and $\mathbf{D}$ dissolved in chloroform show no single signal near $\delta \quad 47.6$ but several signals in the range $\delta 45$ to 48 . This result indicates a degradation of the bicyclic structure in $\mathrm{CHCl}_{3}$. Possibly, chloroform which is not suitable for coordination of Ti atoms, removes the coordinating dioxane or THF molecules from the titanodiphenylsiloxanes and because of this process the titanodiphenylsiloxanes lose their structural stability. The ${ }^{29} \mathrm{Si}$ hNMR spectra of the spirocyclic compound $\mathbf{B}$ dissolved in THF show two signals with chemical shifts $\delta \quad 44.44$ $(-\mathrm{Si}-\mathrm{O}-\mathrm{Si}-\mathrm{O}-\mathrm{Ti}-)$ and $46.06(-\mathrm{Si}-\mathrm{O}-\mathrm{Si}-\mathrm{O}-$ $\mathrm{Si}-\mathrm{O}-\mathrm{Ti}-)$ and with comparable signal intensities corres ponding to the two different types of $\mathrm{Si}$ atoms in its structure. On the basis of the results, signals of the Si atoms

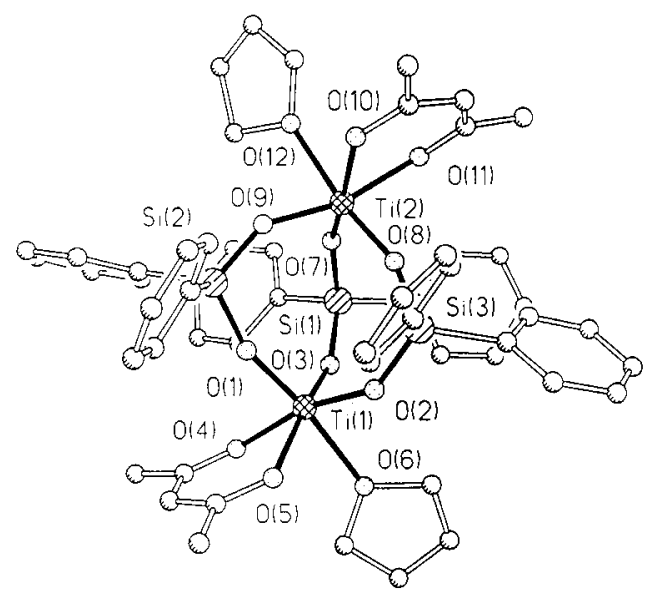

C

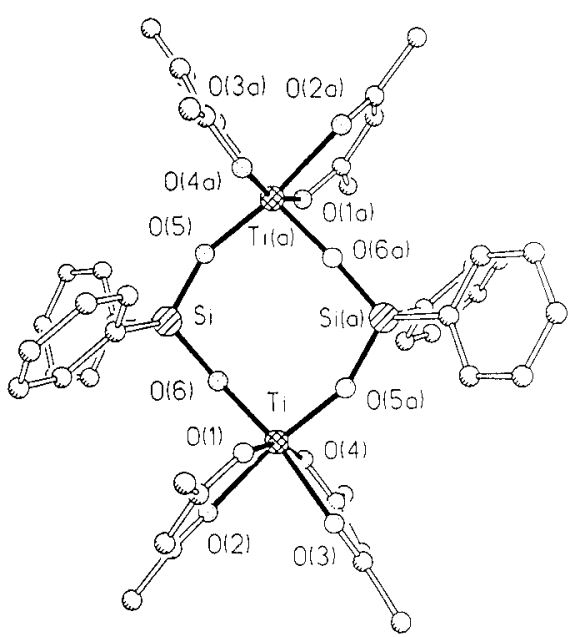

$\mathbf{E}$

Fig. 2 Structures of the bicyclic (C) and cyclotetrameric (E) titanodiphenylsiloxanes 
Table 2 Selected bond lengths ( $\AA$ ) and angles (degrees) in compounds $\mathbf{C}, \mathbf{D}, \mathbf{E}$ and $\mathbf{F}$. (The values for $\mathbf{C}$ were taken from both molecules present in the asymmetric unit cell)

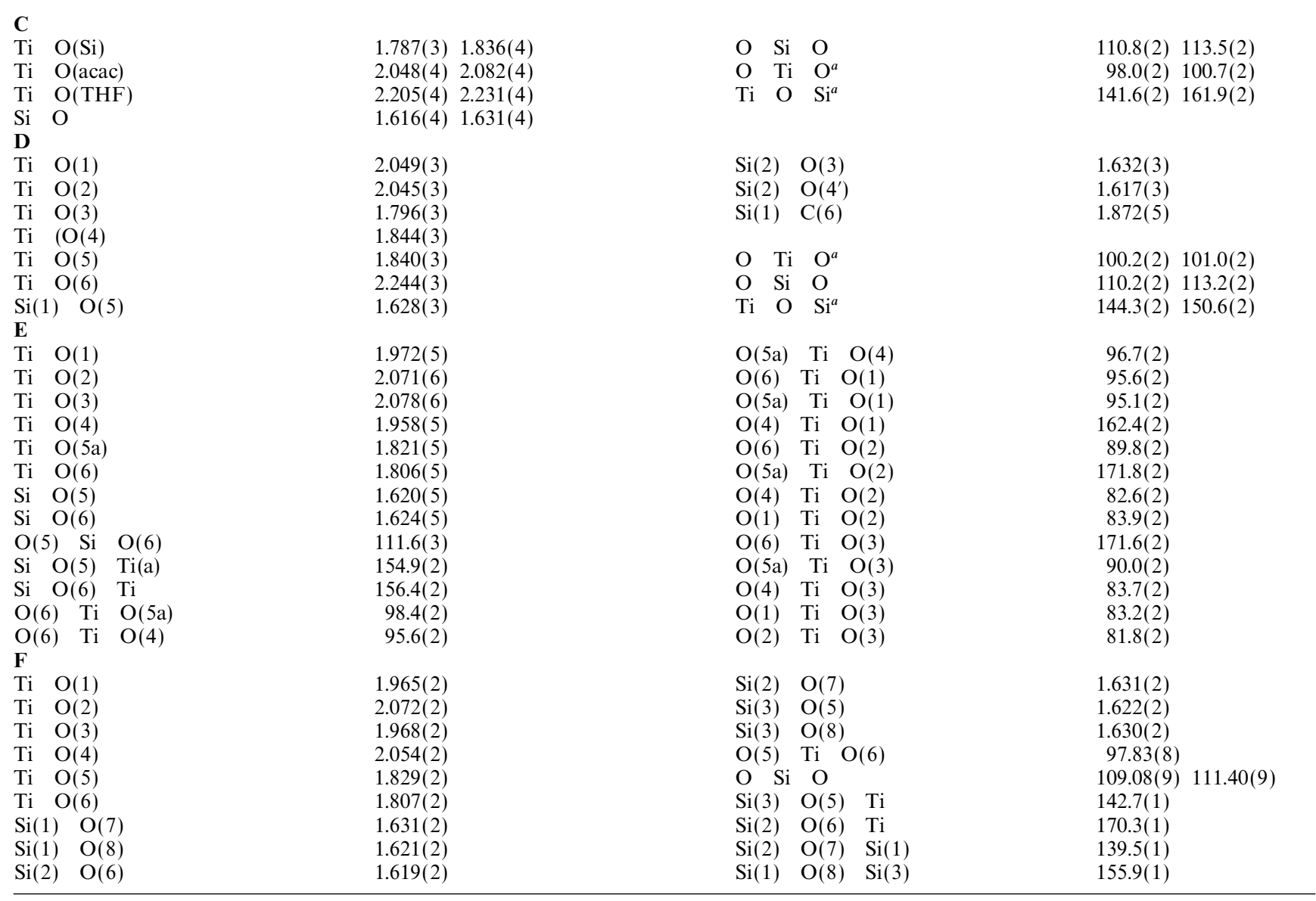

${ }^{a}$ Within the cage.

Table 3 Analytical results for the titanodiphenylsiloxanes A E

\begin{tabular}{|c|c|c|c|c|c|}
\hline & $\mathbf{A}$ & B & C & $\mathbf{D}$ & $\mathbf{E}$ \\
\hline \multicolumn{6}{|l|}{ composition $(\operatorname{mass} \%)^{d}$} \\
\hline $\mathrm{C}$ & $66.1(62.9)$ & $69.2(68.4)$ & $60.0(59.4)$ & $58.0(57.9)$ & $57.2(57.5)$ \\
\hline $\mathrm{H}$ & $4.6(4.9)$ & $4.8(4.9)$ & $5.6(5.6)$ & $5.7(5.8)$ & $5.6(5.7)$ \\
\hline $\mathrm{Si}$ & $12.8(12.9)$ & $13.5(13.7)$ & $7.8(8.4)$ & $7.0(7.6)$ & $5.6(5.8)$ \\
\hline $\mathrm{Ti}$ & $5.5(6.3)$ & $2.9(2.8)$ & $8.9(9.3)$ & $8.0(8.5)$ & $9.5(9.7)$ \\
\hline molecular mass $(\mathrm{TOF})^{d}$ & $873(873)$ & $1666(1666)$ & $1080(936)^{a}$ & no spectrum & $920(920)$ \\
\hline${ }^{29} \mathrm{Si} \mathrm{NMR}$ (in THF), $\delta$ & 45.53 & $44.44, \quad 46.06$ & 47.63 & 47.62 & 48.78 \\
\hline${ }^{29} \mathrm{Si}$ NMR (solid state), $\delta$ & $\begin{array}{l}42.9,(\mathrm{sh}) \quad 43.3 \\
44.2, \quad 45.2\end{array}$ & $\begin{array}{ll}42.7, & 43.0, \\
44.1, & 44.5, \\
44.8, & 45.5, \\
49.4 & \end{array}$ & $\begin{array}{l}47.2, \quad 47.5, \\
47.8, \quad 48.1, \\
48.5\end{array}$ & $44.7, \quad 46.0$, & 49.0 \\
\hline${ }^{17} \mathrm{O}$ NMR, $\delta$ & $\begin{array}{l}64,284 \\
662(<15 \%)^{b}\end{array}$ & $7495,293^{c}$ & $319^{b}$ & & $353,575(<10 \%)^{c}$ \\
\hline IR (region $9001000 \mathrm{~cm}^{1}$ ) & 931 s, $993 w$ & 916s, 993w & $932 \mathrm{~s}$ & $930 \mathrm{~s}$ & $933 \mathrm{~s}, 985 \mathrm{~s}$ \\
\hline
\end{tabular}

${ }^{a}$ Corresponds to removal of solvent. ${ }^{b} \mathrm{In}$ THF. ${ }^{c} \mathrm{In} \mathrm{CHCl}_{3} .{ }^{d}$ Theoretical values; values in parentheses are those found experimentally.

in $-\mathrm{Si}-\mathrm{O}-\mathrm{Si}-\mathrm{O}-\mathrm{Ti}-$ building units $\left[\mathrm{D}^{2}(1 \mathrm{Ti})\right]$ of struc tures $\mathbf{A}$ and $\mathbf{B}$ show a low field shift and those in $-\mathrm{Ti}-\mathrm{O}-\mathrm{Si}-\mathrm{O}-\mathrm{Ti}$ units $\left[\mathrm{D}^{2}(2 \mathrm{Ti})\right]$ of structures $\mathbf{C}, \mathbf{D}$ and E a high field shift compared with $\mathrm{D}^{2}(2 \mathrm{Si})$ units $(\delta$ 47.04) of the octaphenyltetrasiloxanediol in THF. ${ }^{13}$

The solid state ${ }^{29} \mathrm{Si}$ NMR MAS spectra of the titanodiphenyl siloxane $\mathbf{E}$ show a narrow single signal at $\delta$ 49.0. The single signal corresponds to the one symmetrically independent $\mathrm{Si}$ atom as follows from the $\mathrm{X}$ ray analysis. The bicyclic com pound $\mathbf{D}$ shows two signals at $\delta \quad 44.7$ and 46.0 in a $1: 2$ intensity ratio. This spectrum is in line with the crystal structure which shows two identical $\mathrm{Si}$ atoms in positions 1 and 2 and a different one in position 3 . Two symmetrically independent molecules are present in the unit cell of the second bicyclic compound $\mathbf{C}$ with $\mathrm{THF}$ as coordinating ligand. Six different $\mathrm{Si}$ atoms are to be found in the structure and lead to five signals in the solid state ${ }^{29} \mathrm{Si}$ NMR spectrum. One of the signals ( $\delta$ 47.2) shows significantly higher intensity compared to the other signals which can be caused by an overlapping of two signals of similarly symmetric $\mathrm{Si}$ atoms. The assignment of the NMR signals of the spirocyclic compound $\mathbf{B}$ to the $\mathrm{Si}$ atoms in the structure is given in the literature. ${ }^{23}$ Generally, a good agreement can be stated between the results of the $\mathrm{X}$ ray analysis and those of the solid state ${ }^{29} \mathrm{Si}$ NMR.

The ${ }^{17} \mathrm{O}$ NMR spectra of the ${ }^{17} \mathrm{O}$ labelled titanosiloxanes $\mathbf{A}, \mathbf{B}, \mathbf{C}$ and $\mathbf{E}$ in THF or $\mathrm{CHCl}_{3}$ solution show a signal of high intensity in the region between $\delta 284$ and 353 which is attributed to the oxygen atoms in $\mathrm{Si}-\mathrm{O}-\mathrm{Ti}$ bridges according 
to the literature. ${ }^{11,24}$ An additional broad signal in the ${ }^{17} \mathrm{O}$ NMR spectra of the samples $\mathbf{A}$ and $\mathbf{B}$ in the region $\delta 5095$ is caused by the oxygen atom in $\mathrm{Si}-\mathrm{O}-\mathrm{Si}$ bonds. The spectra of the compounds $\mathbf{A}$ and $\mathbf{E}$ show an additional signal with low intensity $(<15 \%)$ at $\delta 662(\mathbf{A})$ and $\delta 573(\mathbf{E})$. The first signal derives from $\mathrm{Ti}-\mathrm{O}-\mathrm{Ti}$ bonds from small impurities of the samples, the second one is caused by the external $\left(\mathrm{CD}_{3}\right)_{2} \mathrm{CO}$ lock.

The FTIR spectra of the titanodiphenylsiloxanes A E all show absorptions in the region $9001000 \mathrm{~cm}^{-1}$ (Table 3). The bands around $930 \mathrm{~cm}^{-1}$ are attributed to stretching vibrations of $\mathrm{Si}-\mathrm{O}-\mathrm{Ti}$ bonds according to the literature. ${ }^{16,25,26}$

\section{Hydrolysis of the titanodiphenylsiloxanes}

The titanodiphenylsiloxanes $\mathbf{A}, \mathbf{B}, \mathbf{C}$ and $\mathbf{D}$ show a high solubility in dioxane and tetrahydrofuran, whereas the cyclo tetrameric titanosiloxane $\mathbf{E}$ is only poorly soluble in these solvents. Nevertheless, for comparison all examinations of the hydrolytic stability of the $\mathrm{Si}-\mathrm{O}-\mathrm{Ti}$ bonds were performed in THF solutions of the samples. The conditions of hydrolysis are an important point for comparing the hydrolytic stability of different structures. Generally, the amount of water is related to the number of $\mathrm{Si}$ or $\mathrm{Ti}$ atoms in the samples. It is better for comparison of the hydrolytic stabilities to relate the amount of water to the number of $\mathrm{Si}-\mathrm{O}-\mathrm{Ti}$ bonds in the molecule. Therefore, two different series were used for the examination of the hydrolytic stability. The first series was performed with the defined molar ratio $(H)$ of water to titanium of $1: 1$ and $6: 1(H=1$ and 6$)$ and a constant $\left(0.5\right.$ and $\left.0.048 \mathrm{~mol}^{-1}\right) \mathrm{Si}$ concentration and for comparison with previous results on indefinite heterometal structures. ${ }^{6,11,13}$ In the second series a constant molar ratio $(K)$ water: $(\mathrm{Si}-\mathrm{O}-\mathrm{Ti})$ bonds of $1: 1$ and Ti concentrations in the range $0.160 .23 \mathrm{~mol} \mathrm{l}^{-1}$ for samples A $\mathbf{D}$ and $0.048 \mathrm{~mol}^{-1}$ for $\mathbf{E}$ were used. The slightly different
Ti concentations for samples A D result from the chosen equal number of hydrolysable $\mathrm{Si}-\mathrm{O}-\mathrm{Ti}$ bonds per volume.

Fig. 3 shows the ${ }^{29} \mathrm{Si}$ and ${ }^{17} \mathrm{O}$ NMR spectra of the spirocyclic compound $\mathbf{A}$ in THF solution before and after hydrolysis at a molar ratio $H=9$ as an example for the degradation of $\mathrm{Si}-\mathrm{O}-\mathrm{Ti}$ bonds by hydrolytic cleavage. The decrease in intensity of the signal at $\delta 284$ in the ${ }^{17} \mathrm{O}$ NMR spectra, attributed to oxygen in $\mathrm{Si}-\mathrm{O}-\mathrm{Ti}$ bonds, with increasing time of hydrolysis reveals the degradation of the $\mathrm{Si}-\mathrm{O}-\mathrm{Ti}$ bonds in the spirocyclic structure A. New signals in the region $\delta 080$ are caused by oxygen atoms in $\mathrm{Si}-\mathrm{O}-\mathrm{Si}(\delta 56)$ and $\mathrm{SiOH}(\mathrm{OR})$ $\left(\begin{array}{l}\delta \\ 27\end{array}\right)$ groups. ${ }^{14}$ With increasing time of hydrolysis the ${ }^{29} \mathrm{Si}$ NMR spectrum shows a decrease in intensity of the signal of the spirocyclic compound and a new signal at $\delta \quad 40.63$ due to tetraphenyldisiloxanediol. ${ }^{13}$ Complete degradation of the $\mathrm{Si}-\mathrm{O}-\mathrm{Ti}$ bonds in the spirocyclic compound $\mathbf{A}$ occurs (both ${ }^{17} \mathrm{O}$ and ${ }^{29} \mathrm{Si}$ NMR measurements) after $20 \mathrm{~h}$ of hydrolysis. The degradation product of the hydrolysis, tetraphenyldisilox anediol containing the stable $\mathrm{Si}-\mathrm{O}-\mathrm{Si}$ bond, is a constituent of the spirocyclic structure $\mathbf{A}$; the structure of the primary hydrolysis product appears to give information on the $\mathrm{Si}$ constituents of the titanodiphenylsiloxane structure. This assumption is supported by the identification of octaphenyl tetrasiloxanediol as a degradation product in the hydrolysate of the spirocyclic compound $\mathbf{B} .{ }^{13}$ Accordingly, the monomeric diphenylsilanediol was found as a degradation product in the hydrolysates of the compounds $\mathbf{C}, \mathbf{D}$ and $\mathbf{E}$ by means of ${ }^{29} \mathrm{Si}$ NMR spectroscopy.

In the following, the results of the ${ }^{29} \mathrm{Si}$ NMR spectroscopic analyses of the hydrolysates and their dependence with time were used for the examination of the hydrolytic stability of the $\mathrm{Si}-\mathrm{O}-\mathrm{Ti}$ bonds in titanodiphenylsiloxanes.

Hydrolysis at molar ratios $\boldsymbol{H}=\mathbf{1}$ and 6. The results of the ${ }^{29} \mathrm{Si}$ NMR spectroscopic examination of the hydrolytic stability

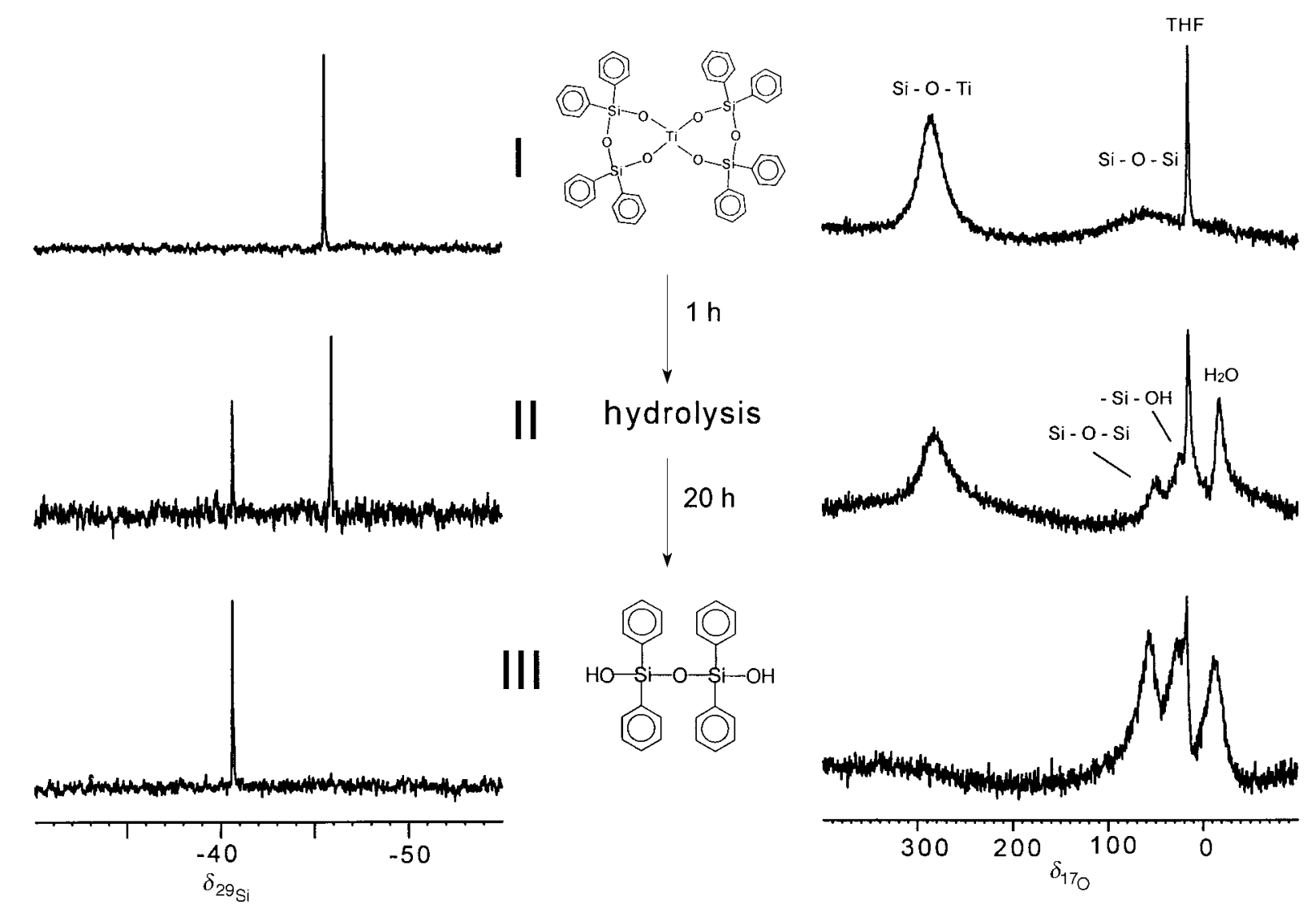

Fig. $3{ }^{29} \mathrm{Si}$ and ${ }^{17} \mathrm{O}$ NMR spectra of the spirocyclic titanodiphenylsiloxane $\mathbf{A}$ before (I), after $1 \mathrm{~h}$ (II) and $20 \mathrm{~h}$ (III) hydrolysis at $H=9$, (reproduced by permission of the Materials Research Society from ref. 14) 
of the titanodiphenylsiloxanes $\mathbf{A} \mathbf{E}$ at $H=1$ and 6 are summar ised in Fig. 4 and 5. From Fig. 4, it can be seen that the cyclotetrameric titanodiphenylsiloxane $\mathbf{E}$ and the spirocyclic structures $\mathbf{A}$ and $\mathbf{B}$ show a high hydrolytic stability in the range of $90100 \%$ of their $\mathrm{Si}-\mathrm{O}-\mathrm{Ti}$ bonds at $\mathrm{H}=1$ up to $1 \mathrm{~d}$. The sample $\mathbf{E}$ also shows a high stability after $7 \mathrm{~d}$, whereas $3050 \%$ of the heterometal bonds were cleaved in the hydrolys ates $\mathbf{A}$ and $\mathbf{B}$ after the same hydrolysis time. The much lower $\mathrm{Si}$ or $\mathrm{Ti}$ concentration in the hydrolysate of $\mathbf{E}$ in comparison to $\mathbf{A}$ and $\mathbf{B}$ influences its hydrolytic degradation but only to some extent. The bicyclic structures $\mathbf{C}$ and $\mathbf{D}$ are already decomposed at $H=1$ by $5060 \%$ after $0.5 \mathrm{~h}$ and to an extent of $90 \%$ after $7 \mathrm{~d}$. As expected no significant difference in the stability of $\mathbf{C}$ and $\mathbf{D}$ is detected owing to the same basic structure of these molecules. A decreasing hydrolytic stability follows from the results in the order cyclotetramer $(\mathbf{E})>$ spirocyclo $(\mathbf{A}, \mathbf{B})>$ bicyclo $(\mathbf{C}, \mathbf{D})$.

The spirocyclic compounds $\mathbf{A}$ and $\mathbf{B}$ and the cyclotetrameric structure $\mathbf{E}$ show a significant degradation of their structure with increasing hydrolysis time at a higher molar ratio of water to $\mathrm{Ti}(H=6)$. About $20 \%$ of compounds A and B are already hydrolysed after $0.5 \mathrm{~h}$ and about $4560 \%$ after $8 \mathrm{~h}$ hydrolysis time (Fig. 5). The bicyclic structures $\mathbf{C}$ and $\mathbf{D}$ are degraded to an extent of $90 \%$ after $0.5 \mathrm{~h}$ hydrolysis time at $H=6$. A decreased hydrolytic stability for all examined struc tures is seen upon increasing the ratio of water to Ti. The difference in the stability of the titanosiloxane structures toward hydrolysis at $H=6$ is nearly in the same order as at $H=1$ : viz., cyclotetramer $(\mathbf{E})>$ spirocyclo $(\mathbf{B})>$ spirocyclo $(\mathbf{A})>$ bicyclo $(\mathbf{C}, \mathbf{D})$.

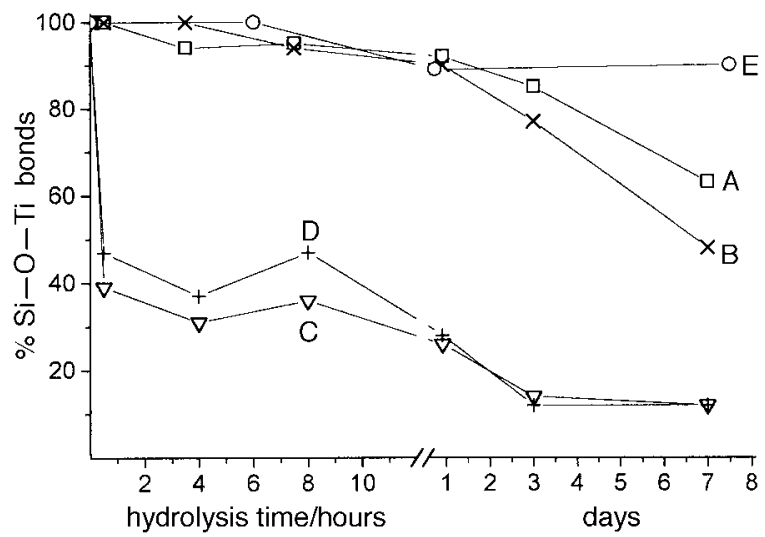

Fig. 4 Hydrolytic degradation of the $\mathrm{Si} \mathrm{O}$ Ti bonds in the titano diphenylsiloxanes A D $\left[c(\mathrm{Si})=0.5 \mathrm{moll}^{1}\right]$ and $\mathbf{E} \quad[c(\mathrm{Si})=$ $\left.0.048 \mathrm{moll}^{1}\right]$ at $H=1$ vs. time

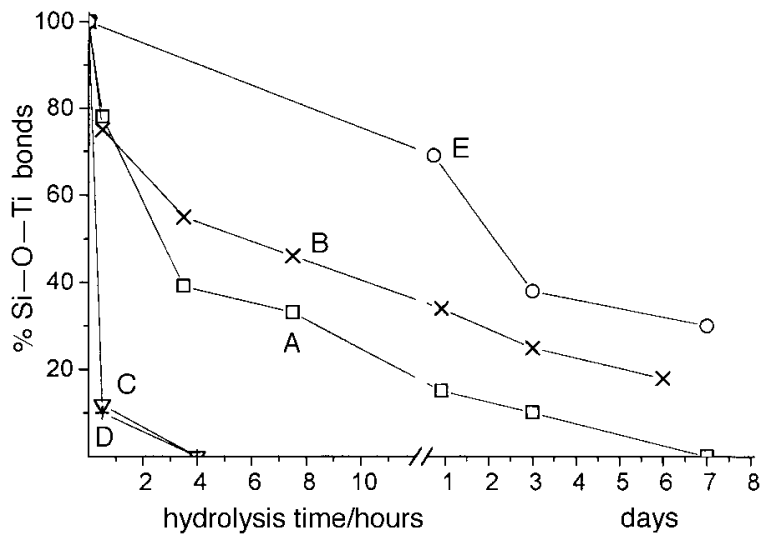

Fig. 5 Hydrolytic degradation of the $\mathrm{Si} \mathrm{O}$ Ti bonds in the titano diphenylsiloxanes A D $\left[c(\mathrm{Si})=0.5 \mathrm{moll}^{1}\right]$ and $\mathbf{E} \quad[c(\mathrm{Si})=$ $\left.0.048 \mathrm{~mol}^{1}{ }^{1}\right]$ at $H=6 \mathrm{vs}$. time
Hydrolysis at molar ratio $K=1$. At $K=1\left(\mathrm{H}_{2} \mathrm{O}: \mathrm{Si}-\mathrm{O}-\mathrm{Ti}\right.$ bond =1) $H$ values in the examined hydrolyses are as follows: $\mathbf{A}$ and $\mathbf{B}: H=4, \mathbf{C}$ and $\mathbf{D}: H=3, \mathbf{E}: H=2$. Thus, an identical amount of water per $\mathrm{Si}-\mathrm{O}-\mathrm{Ti}$ bond in the molecules $(K=$ 1) corresponds to different amounts of water per titanium atom. The results of the ${ }^{29} \mathrm{Si}$ NMR spectroscopic examination of the hydrolytic stability at $K=1$ are summarised in Fig. 6 . The high hydrolytic stability of the cyclotetrameric structure $\mathbf{E}$ is again remarkable. The spirocyclic compounds $\mathbf{A}$ and $\mathbf{B}$ show a degradation of their structure of $c a .40 \%$ after $0.5 \mathrm{~h}$. A larger discrepancy in their hydrolytic stabilities is observed with increasing hydrolysis time. The spirocyclic structure A containing six membered rings is more stable than $\mathbf{B}$ containing ten membered rings ( $4 \mathrm{~h}$ hydrolysis time). A similar degra dation of $c a .90 \%$ is, however, found after longer hydrolysis times $(3 \mathrm{~d})$. The bicyclic structures $\mathbf{C}$ and $\mathbf{D}$ again show the highest degradation $(6070 \%)$ in the hydrolysates after $0.5 \mathrm{~h}$. The degradation rates of the bicyclic structures are closer to that of the spirocyclic compound $\mathbf{B}$ after $4 \mathrm{~h}$ hydrolysis time. It can be seen from Fig. 6 that the titanodiphenylsiloxane structures A D degrade to an extent of $8590 \%$ after $3 \mathrm{~d}$. Comparing the results of hydrolysis at $H=1$ and 6 with those at $K=1$ it follows that the order in the hydrolytic stability of the various structures is the same but more moderate at $K=1$ when the amount of water is related to the number of $\mathrm{Si}-\mathrm{O}-\mathrm{Ti}$ bonds. Nevertheless, in all cases, significant differ ences in the hydrolytic stability can be detected which depends on the titanodiphenylsiloxane structure.

Besides the examination of the hydrolytic stabilities of the titanodiphenylsiloxanes at $H=1$ and 6 the hydrolysates of bicyclic compounds $\mathbf{C}$ and $\mathbf{D}$ were also studied at the high molar ratio $\mathrm{H}_{2} \mathrm{O}: \mathrm{Ti}=20$. Crystals appeared in low yield in the hydrolysates after a reaction time of $24 \mathrm{~h}$. The crystals were identified by $\mathrm{X}$ ray structural analysis as the cyclotetra meric titanodiphenylsiloxane $\mathbf{F}$ with only one Ti atom in the ring which is complexed by two acac ligands (Table 1). The result reveals that in the hydrolysates a partial reorganisation of the bicyclic structures $\mathbf{C}$ or $\mathbf{D}$ occurs via monomeric diphenylsilanediol units to more stable cyclotetrameric struc tures. The establishment of structure $\mathbf{F}$ is only possible by a partial hydrolysis of the acac ligands at the $\mathrm{Ti}$ atoms ${ }^{27}$ in structures $\mathbf{C}$ or $\mathbf{D}$ and the reaction of the released acac molecules with existing mono complexed $\mathrm{Ti}$ atoms in the hydrolysate. These results allow a first insight into the compli cated reaction mechanism in hydrolysates of titano diphenylsiloxanes.

Finally, the influence of the Si concentration in the hydrolys ates on the degradation rate was examined comparing a dilute hydrolysate of sample $\mathbf{E}$ with the other samples. Fig. 7 shows the hydrolytic stability of the spirocyclic sample B measured

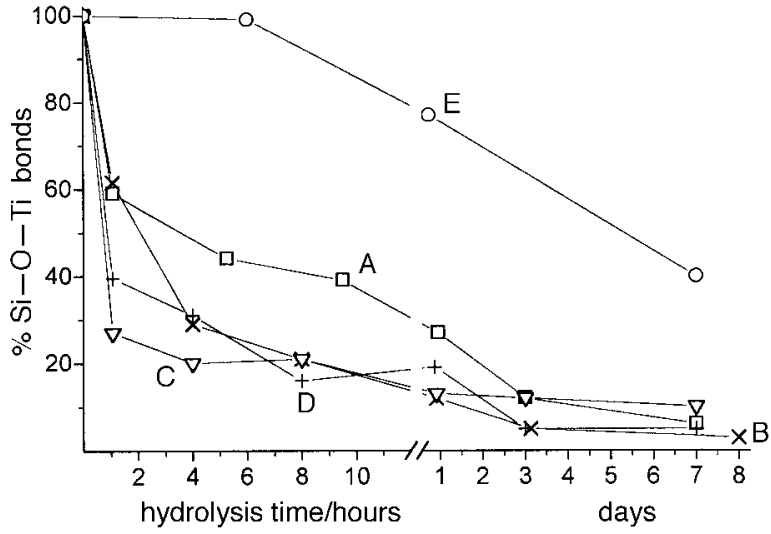

Fig. 6 Hydrolytic degradation of the $\mathrm{Si} \mathrm{O} \mathrm{Ti}$ bonds in the titano diphenylsiloxanes $\mathbf{A}$ and $\mathbf{B}\left[c(\mathrm{Ti})=0.16 \mathrm{moll}{ }^{1}\right], \quad \mathbf{C}$ and $\mathbf{D}$ $\left(0.23 \mathrm{~mol} \mathrm{l}^{1}\right)$ and $\mathbf{E}\left(0.048 \mathrm{~mol} \mathrm{l}^{1}\right)$ at $K=1$ vs. time 
at $c(\mathrm{Ti})=0.024 \mathrm{~mol}^{-1}$ and those of the cyclotetrameric com pound $\mathbf{E}\left[c(\mathrm{Ti})=0.048 \mathrm{moll}^{-1}\right]$ at $K=1$. The different $\mathrm{Ti}$ concentrations result from the chosen equal number of $\mathrm{Si}-\mathrm{O}-\mathrm{Ti}$ bonds per volume. For comparison, the curve of compound $\mathbf{B}$ at $c(\mathrm{Ti})=0.16 \mathrm{moll}^{-1}\left[c(\mathrm{Si})=1.28 \mathrm{moll}^{-1}\right]$ is added in Fig. 7. The result shows that a decreased concen tration of $\mathbf{B}$ in the hydrolysate leads to a slightly increased hydrolytic stability of the $\mathrm{Si}-\mathrm{O}-\mathrm{Ti}$ bonds. Nevertheless, the stability of $\mathbf{B}$ in both dilute and concentrated solutions is significantly lower than the stability of the cyclotetrameric compound $\mathbf{E}$.

The examination of the effect of $\mathrm{H}^{+}$concentration in the hydrolysate $\left(1.1 \times 10^{-3} \mathrm{M} \mathrm{HCl}\right)$ on the hydrolytic stability of the $\mathrm{Si}-\mathrm{O}-\mathrm{Ti}$ bonds at $K=1$ showed no experimentally significant differences compared with the hydrolysates obtained from water $(\mathrm{pH}=6.7)$.

The reason for the high hydrolytic stability of the cyclotetra meric titanodiphenylsiloxane $\mathbf{E}$ could be the presence of the low strained eight membered ring $c f$. siloxanes. ${ }^{28}$ Further reasons for the stability of $\mathbf{E}$ are the shielding of the $\mathrm{Si}$ and Ti atoms by the large phenyl and acac ligands which can reduce the contact of the water with the metal atoms as well as the stable six coordination of $\mathrm{Ti}$ atom by oxygen. The Ti atoms in the bicyclic structures $\mathbf{C}$ and $\mathbf{D}$ likewise show six coordi nation but this includes weak bonds to dioxane or tetrahydro furan molecules. The weakness of these bonds in $\mathbf{C}$ and $\mathbf{D}$ is supported by the results of the time of flight experiments (no mass spectrum for $\mathbf{D}$, basic mass spectrum of $\mathbf{C}$ without coordinating solvent) and the rapid degradation of structures $\mathbf{C}$ and $\mathbf{D}$ in $\mathrm{CHCl}_{3}$ solution owing to the easy removal of the stabilising dioxane or THF molecules. Exchange of the solvent molecules in $\mathbf{C}$ and $\mathbf{D}$ by water should be rapid followed by a

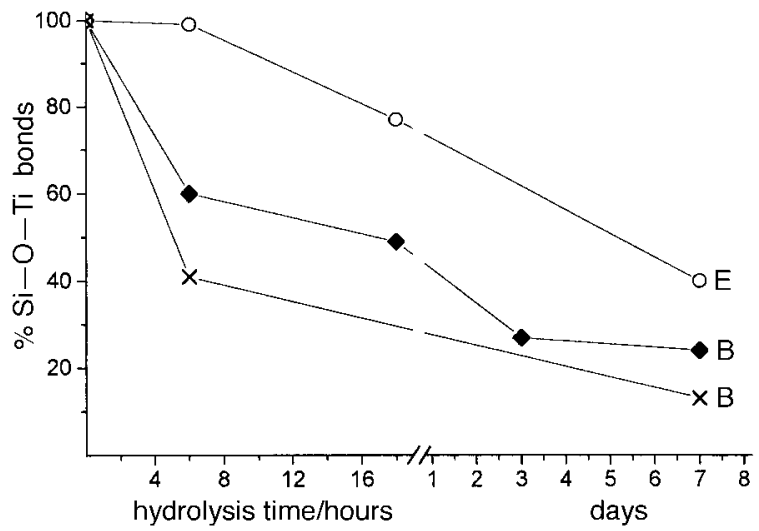

Fig. 7 Hydrolytic degradation of the $\mathrm{Si} \mathrm{O}$ Ti bonds in the titano diphenylsiloxanes $\mathbf{B}\left[c(\mathrm{Ti})=0.024(\bullet)\right.$ and $\left.0.16 \mathrm{~mol} \mathrm{l}^{1}(\times)\right]$ and $\mathbf{E}$ $\left(0.048 \mathrm{moll}^{1}\right.$; $\left.\bigcirc\right)$ at $K=1 \mathrm{vs}$. time quick hydrolytic attack on $\mathrm{Si}-\mathrm{O}-\mathrm{Ti}$ bonds according to the mechanism in Fig. 8. The released hydroxylated titanium species condense to higher molecular complexed titanium oxide hydroxides whereas the primarily formed diphenylsilanediol partially condenses under the catalytic influence of Ti species to tetraphenyldisiloxanediol and octaphenyltetrasiloxanediol. ${ }^{18}$ Probably, the medium hydrolytic stability of the $\mathrm{Si}-\mathrm{O}-\mathrm{Ti}$ bonds in the spirocyclic structures $\mathbf{A}$ and $\mathbf{B}$ is primarily caused by the shielding effect of the directly neighbouring eight phenyl groups to the Ti atom and the induction effect of the phenyl groups on the $\mathrm{Si}$ atom which lowers the charge difference between the $\mathrm{Si}$ and $\mathrm{Ti}$ atoms and increases the hydrolytic stability of the oxygen bridged heterometal bond.

\section{Conclusions}

The investigation of titanodiphenylsiloxanes with different structures by $\mathrm{X}$ ray structural analysis, NMR and IR spectro scopies and time of flight mass spectrometry results in a good correlation of the different experimental data. Furthermore, the results show that all examined titanodiphenylsiloxanes of different structures undergo hydrolytic degradation of their $\mathrm{Si}-\mathrm{O}-\mathrm{Ti}$ bonds. Relatively stable monomeric, dimeric or tetrameric siloxane structures are primary products of the hydrolysis which appear as building blocks in the original titanosiloxane structures. The cyclotetrameric titanodiphenyl siloxane structure $\mathbf{E}$ shows the highest hydrolytic stability followed by the spirocyclic structures $\mathbf{A}$ and $\mathbf{B}$ and finally by the bicyclic structures $\mathbf{C}$ and $\mathbf{D}$. The different shielding of the metal atoms, induction effects of the ligands and differences in the stability of the six fold Ti coordination by non complexing solvent molecules are assumed as reasons for the differences in the hydrolytic stability of the titanodiphenylsiloxanes. The results show that, generally, it cannot be said that all $\mathrm{Si}-\mathrm{O}-\mathrm{Ti}$ bonds are equally unstable towards hydrolysis, rather it depends on the structure of the titanosiloxanes, the ligands and the hydrolytic conditions (e.g. amount of water, concen tration of the sample). The results reveal that an integration of hydrolytically stable heterometal bonds in materials via the sol gel process with the aim of highly homogeneous structures requires detailed knowledge of the chemical compositions, the structure of the building units and the hydrolytic stability of the species. Thus, the results of this work can contribute to a better understanding of the problems concerning the homogen eity of sol gel derived materials on a molecular scale.

The authors gratefully acknowledge Ms S. Carstensen and Ms S. Korte for experimental and organisational work, Dr P. Toledano (Chimie de la Matière Condensée, Université P. et M. Curie, Paris) for support in X ray crystallographic analysis, Dr R. P. Krüger (Institut für Angewandte Chemie,
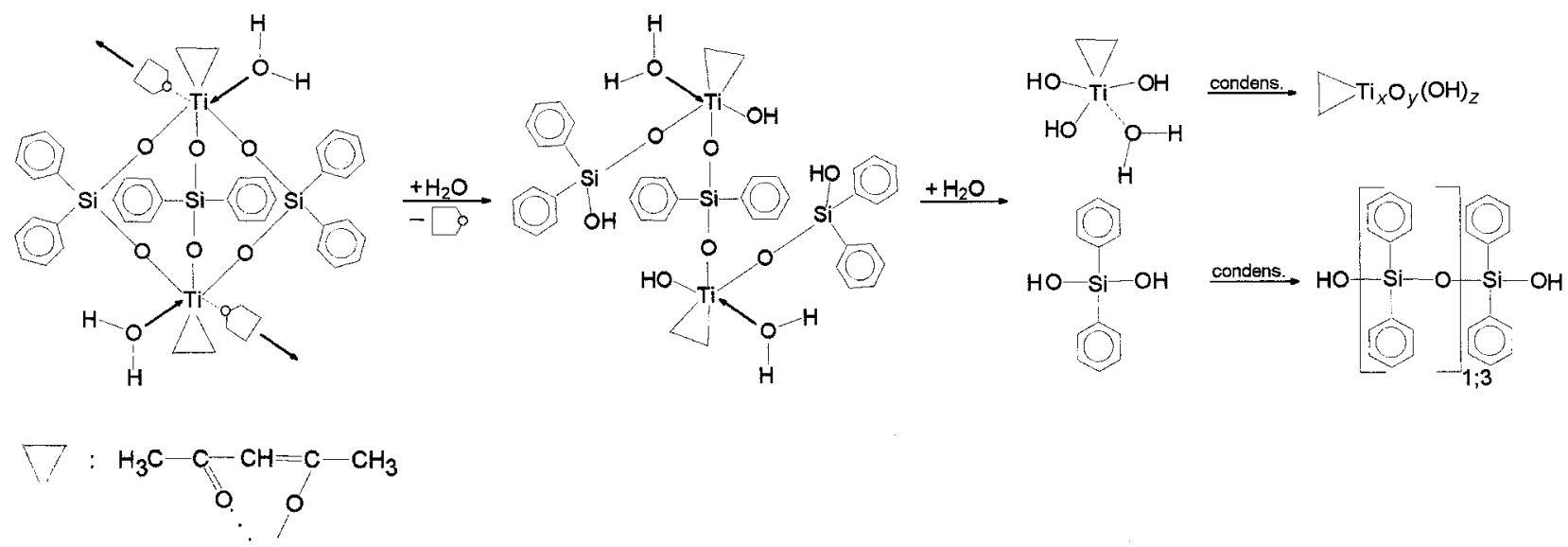

Fig. 8 Scheme of the hydrolysis reaction of the bicyclic titanodiphenylsiloxane $\mathbf{C}$ 
Berlin) for time of flight measurements and Dipl. Chem. T. Reinert for his help in NMR measurements.

\section{References}

1 J. D. Mackenzie and D. R. Ulrich, Ultrastructure Processing of Advanced Materials, J. Wiley, New York, 1988.

2 I. M. Thomas, in Sol Gel Technology for Thin Films, Fibers, Preforms, Electronics, and Specialty Shapes, ed. L. C. Klein, Noyes Publications, Park Ridge, NJ, 1988.

3 R. C. Mehrotra, Chemistry, Spectroscopy and Application of Sol Gel Glasses, ed. R. Reisfeld and C. K. Jorgensen, Springer Verlag, Berlin, Heidelberg, 1992.

4 H. Schmidt, J. Non Cryst. Solids, 1988, 100, 51.

5 C. J. Brinker and C. W. Scherer, Sol Gel Science, Academic Press, New York, 1990

6 T. Nishide, F. Mizukami and H. Yamaguchi, J. Sol Gel Sci. Technol., 1994, 1, 113

7 A. Kasgoz, K. Yoshimura, T. Misono and Y. Abe, J. Sol Gel Sci. Technol., 1994, 1, 185.

8 H. Schmidt and B. Seiferling, Mater. Res. Soc. Symp. Proc., 1986, 73, 739 .

9 J. Jonas, A. D. Irwin and J. S. Holmgren, in Ultrastructure Processing of Advanced Materials, ed. D. R. Uhlmann and D. R. Ulrich, J. Wiley, 1992, pp. 303314.

10 C. L. Schutte, J. R. Fox, R. D. Boyer and D. R. Uhlmann, in Ultrastructure Processing of Advanced Materials, ed. D. R. Uhlmann and D. R. Ulrich, J. Wiley, 1992, pp. 95102.

11 F. Babonneau, Mater. Res. Soc. Symp. Proc., 1994, 346, 949.

12 F. Babonneau, J. Maquet, and J. Livage, Proc. Int. Symp. Sol Gel Sci. Technol., Los Angeles, 1994.
13 D. Hoebbel, T. Reinert and H. Schmidt, J. Sol Gel Sci. Technol., 1996, 6, 139.

14 D. Hoebbel, T. Reinert and H. Schmidt, Mater. Res. Soc. Symp. Proc. Ser., 1996, 435, 461.

15 K. A. Andrianov, N. A. Kurasheva and L. I. Kuteinikova, Izv. Akad. Nauk SSSR, Ser. Khim., 1977, 10, 2314.

16 K. A. Andrianov, N. A. Kurasheva and L. I. Kuteinikova, Zh. Obshch. Khim., 1976, 46, 1533.

17 V. A. Zeitler and C. A. Brown, J. Am. Chem. Soc., 1957, 79, 4618.

18 D. Hoebbel, T. Reinert and H. Schmidt, J. Sol Gel Sci. Technol., 1996, 7, 217.

19 M. B. Hursthouse and M. A. Hossain, Polyhedron, 1984, 3, 95.

20 D. Smith, C. N. Caughlan and J. A. Campbell, Inorg. Chem., 1972, 11, 2989.

21 P. Toledano, M. In and C. Sanchez, C. R. Acad. Sci. Paris, 1991, 313, 1247.

22 M. Veith, M. Jarczyk and V. Huch, Angew. Chem., Int. Ed. Engl., 1997, 36, 117.

23 N. M. Rutherford, Ph. D. Thesis, University of California, 1987.

24 V. W. Day, T. A. Eberspacher, W. G. Klemperer, C. W. Park and F. S. Rosenberg, J. Am. Chem. Soc., 1991, 113, 8190.

25 V. A. Zeitler and C. A. Brown, J. Phys. Chem., 1957, 61, 1174.

26 M. Aizawa, Y. Nosaka and N. Fujii, J. Non Cryst. Solids, 1991, 128, 77.

27 D. Hoebbel, T. Reinert, H. Schmidt and E. Arpac, J. Sol Gel Sci. Technol., 1997, 10, 115.

28 W. Noll, Chemie und Technologie der Silicone, Verlag Chemie, Weinheim, 1968.

29 G. M. Sheldrick, Programs for Crystal Structure Determination, SHELXS and SHELXL, University of Gottingen. 